\title{
Quality of life and perceived health status in adults with congenitally corrected transposition of the great arteries
}

\author{
Timothy Cotts, MD, ${ }^{\text {a,b }}$ Sanjana Malviya, ${ }^{\mathrm{a}}$ and Caren Goldberg, MD, MS ${ }^{\mathrm{a}}$
} Objective: The purpose of this study is to assess perceived health status and quality of life in adults with con-
genitally corrected transposition of the great arteries who have not undergone anatomic repair.

\begin{abstract}
Methods: Quality of life as measured by the satisfaction with life scale and linear analog scales and perceived health status as measured by the Short Form 36 Health Survey (version 1) were evaluated in 25 adults with congenitally corrected transposition and compared with a control group of 25 adults with mild, hemodynamically insignificant defects.
\end{abstract}

Results: Instruments were returned by $83 \%$ of patients $(25 / 30 ; 11$ male; mean age, $44.6 \pm 16$ years). Health status by the linear analog scale was significantly lower $(P=.03)$ in subjects (median, 80; range, 15-100) than in controls (median, 85; range, 65-100). Quality of life by the satisfaction with life scale was also lower $(P=.009)$ in subjects (mean, $24 \pm 8$ ) compared with controls. Age was negatively correlated with the Short Form 36 Health Survey physical functioning $(r=-0.41, P=.04)$, bodily pain $(r=-0.5, P=.01)$, and physical component $(r=-0.56, P=.004)$ summary scores in adults with congenitally corrected transposition but not in controls.

Conclusions: Adults with congenitally corrected transposition have lower reported health status and satisfaction with life than a control population, with perceived health status declining with advancing age. (J Thorac Cardiovasc Surg 2012;143:885-90)

Congenitally corrected transposition of the great arteries (CCTGA) is a rare congenital heart defect characterized by atrioventricular and ventriculo-arterial discordance. The presentation and natural history can be extremely variable and are dependent on the presence or absence of coexisting lesions, including ventricular septal defect, pulmonary stenosis, and tricuspid valve function. Heart block is also a common complication, increasing in frequency with advancing age. The development of congestive heart failure is common, occurring with increasing frequency as patients reach their fourth and fifth decades of life. ${ }^{1}$ The historical approach to care of these patients has depended on the existence of coexisting lesions. In patients with isolated CCTGA, conservative management has been favored. In patients with ventricular septal defects and left ventricular outflow tract obstruction, ventricular septal defect closure and relief of left ventricular outflow tract obstruction have been performed. In the current surgical era, many centers favor anatomic repairs, establishing the left ventricle as the systemic ventricle and

\footnotetext{
From the Division of Cardiology, ${ }^{a}$ Department of Pediatrics, and Division of Cardiology, ${ }^{\mathrm{b}}$ Department of Internal Medicine, University of Michigan Medical School, Ann Arbor, Mich.

Disclosures: Authors have nothing to disclose with regard to commercial support.

Received for publication June 13, 2011; revisions received Aug 2, 2011; accepted for publication Aug 25, 2011; available ahead of print Sept 28, 2011.

Address for reprints: Timothy Cotts, MD, L1242 Women's Box 5204, 1500 E. Medical Center Dr, Ann Arbor, MI 48109-5204 (E-mail: cottstim@umich.edu). $0022-5223 / \$ 36.00$

Copyright (c) 2012 by The American Association for Thoracic Surgery doi:10.1016/j.jtcvs.2011.08.031
}

the right ventricle as the subpulmonary ventricle. In patients without severe pulmonary stenosis or pulmonary atresia, a double switch procedure is performed, whereas patients with pulmonary outflow tract obstruction undergo a Senning-Rastelli procedure, in which a conduit is placed between the right ventricle and the pulmonary arteries. Quality of life (QOL) and perceived health status in adults with CCTGA have not been studied specifically. Understanding the long-term functional status and QOL of adults with CCTGA is important for identifying the optimal treatment strategies for current patients and the optimal therapeutic approach for infants and children with congenitally corrected transposition. Demonstration of poor functional status and QOL in adults undergoing historical approaches to management might help to justify the short-term morbidity and mortality associated with anatomic repairs. We hypothesized that perceived health status and QOL would be lower in patients with congenitally corrected transpositions compared with a control population, and that there would be an age-dependent decrease in health status and patient-reported QOL.

\footnotetext{
MATERIALS AND METHODS

Clinical databases of the pediatric cardiology and adult congenital heart programs were searched for patients with congenitally corrected transposition physiology. Patients with $\{\mathrm{S}, \mathrm{L}, \mathrm{L}\}$ and $\{\mathrm{I}, \mathrm{D}, \mathrm{D}\}$ anatomy were included. Patients who had undergone single-ventricle palliations were excluded. A study packet involving a questionnaire of basic demographic items and a series of survey instruments assessing perceived health status and patient-reported QOL was sent to patients. A control group consisting of asymptomatic (New York Heart Association class I) adults with simple congenital heart disease (repaired ventricular septal defects, atrial septal
} 


\author{
Abbreviations and Acronyms \\ CCTGA $=$ congenitally corrected transposition of \\ the great arteries \\ LAS = linear analog scale \\ QOL = quality of life \\ SF-36 = Short Form 36 Health Survey \\ SWLS = satisfaction with life scale
}

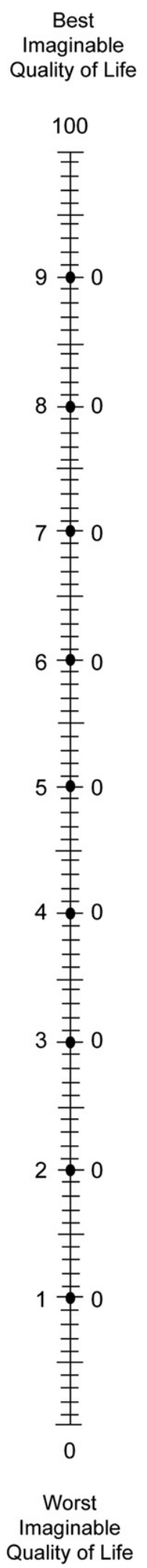

defects, and small, unrepaired ventricular septal defect) also was recruited. For the purposes of this study, perceived health status was differentiated from QOL measures. QOL was defined per previous studies as "sense of overall life satisfaction that is positively or negatively influenced by an individual's perception of certain aspects of life that are important to them, including matters both related and unrelated to health.", ${ }^{, 3}$ Health status was measured using the Short Form 36 Health Survey (SF-36), version 1 , and a linear analog scale (LAS). QOL was measured using the satisfaction with life scale (SWLS) and a LAS. Approval was obtained from the institutional review board, and informed consent required for participation.

\section{Variables and Measurement}

Short Form 36 Health Survey. The SF-36 is an extensively used and well-validated instrument using 36 questions to assess perceived health status across both physical and emotional domains. ${ }^{4-6}$ The physical components include physical function, role physical, bodily pain, and general health. These scores form the basis for the physical component summary score. The physical function and role physical subscales assess an individual's perception of his/her ability to perform physical activities and to work and perform activities, respectively. The bodily pain subscale assesses any limitations based on pain, whereas the general health subscale is an overall assessment of one's health status. The mental components include vitality, social function, role emotional, and mental health. These scores form the basis for the mental component summary score. The vitality subscale addresses the overall energy level of a subject, and the social function subscale addresses the degree of limitation in activities due to physical and emotional problems. The role emotional subscale assesses problems with work and daily activities as a result of emotional problems, and the mental health subscale serves as a general screen for psychiatric issues (particularly anxiety and depression). The SF-36 instrument was selected because SF-36 data can be normalized to a scale such that 50 is a normal score allowing for comparison of both the study and control populations with established normal values.

Linear analog scale. Both perceived health status and QOL were measured using a LAS, which is a vertically oriented line $10 \mathrm{~cm}$ in length with gradients marked and labeled at each centimeter (Figure 1). For health status, respondents were asked to indicate their health state from 0 to 100, with best possible health state being 100 and worse possible health state being 0 . Likewise, for QOL, on a separate scale, respondents were asked to indicate their QOL from 0 to 100 . The LAS is a relatively simple measure that has been found to have good validity and reliability. ${ }^{7,8}$

Satisfaction with life scale. The SWLS also was used as a measure of QOL. The SWLS is a 5-question survey asking respondents to agree or disagree with statements regarding their satisfaction with their life situation. ${ }^{9}$ A 7-point scoring scale is used, ranging from strong disagreement with the statement scoring 0 points to strong disagreement with the statement scoring 7 points. This gives a maximal score of 35 and a minimal score of 0 . A score of 30 to 35 indicates an individual very highly satisfied
FIGURE 1. The LAS for QOL. Subjects were asked to identify their perceived QOL on a scale from 0 to 100 . 
TABLE 1. Baseline demographics for patients with congenitally corrected transposition of the great arteries and controls

\begin{tabular}{lccc}
\hline \multicolumn{1}{c}{ Characteristic } & $\begin{array}{c}\text { CCTGA group } \\
(\mathbf{n}=\mathbf{2 5})\end{array}$ & $\begin{array}{c}\text { Control group } \\
(\mathbf{n = 2 5})\end{array}$ & $\boldsymbol{P}$ value \\
\hline Sex & & & \\
$\quad$ Male & $11(44 \%)$ & $11(44 \%)$ & 1 \\
Age (mean \pm SD) & $42.6 \pm 15.6$ & $39.7 \pm 14.5$ & .5 \\
Marital status & & & $.14 *$ \\
$\quad$ Married & $13(52 \%)$ & $19(76 \%)$ & \\
Single & $8(32 \%)$ & $5(20 \%)$ & \\
Divorced & $3(12 \%)$ & 0 & \\
$\quad$ Widowed & $1(4 \%)$ & $1(4 \%)$ & \\
Level of education & & & .78 \\
College graduate & $14(56 \%)$ & $13(52 \%)$ & $.57 \dagger$ \\
$\quad$ or beyond & & & \\
Employment status & & 16 & \\
Employed & 13 & 0 & \\
Out of work & 2 & 3 & .15 \\
Homemaker & 3 & 3 & \\
Student & 1 & 2 & \\
Retired & 4 & 1 & \\
$\quad$ Unable to work & 2 & $8(32 \%)$ & \\
Previous cardiac surgery & $14(56 \%)$ & 0 & \\
Pacemaker & $7(28 \%)$ & & \\
\hline
\end{tabular}

$P$ values of $<.05$ are shown in bold. $S D$, Standard deviation. *Because of small sample size, marital status was dichotomized to married/not married for purposes of comparison between subjects and controls. †Employment status was dichotomized to employed/not employed for purposes of comparison.

with life, a score of 20 to 24 is considered an average score, and scores of 15 to 19,10 to 14 , and 5 to 9 are consistent with individuals who are slightly dissatisfied, dissatisfied, and extremely dissatisfied with their lives, respectively. The SWLS has been studied and validated in a variety of disease and non-disease states. The highest reported score was for male FrenchCanadian adults (mean, $27.9 \pm 5.7$ ), and the lowest reported score was for inpatients at a veterans affairs hospital (mean, $11.8 \pm 5.6$ ). ${ }^{10}$ The SWLS has been shown to have good correlation with the LAS for QOL. ${ }^{3}$

\section{Statistical Analysis}

Statistical analysis was performed using GraphPad Prism version 5.01 for Windows (GraphPad Software, San Diego, Calif). Normally distributed data were reported as means \pm standard deviation, and non-normally data were repeated as medians (range). Categoric data were analyzed using the Fisher exact test. Normally distributed continuous data were analyzed using $t$ tests, and non-normally distributed continuous data were analyzed using the Mann-Whitney test. In our relatively small group, among the SF-36 data, data from some subscales were normally distributed and others were not. For consistency, all data from the SF-36 were therefore analyzed with the Mann-Whitney test. Correlation analysis was performed using Pearson's correlation for normally distributed data and Spearman's correlation for non-normally distributed data.

\section{RESULTS}

Of 30 questionnaires sent to patients with CCTGA, 25 were returned, for a response rate of $83 \%$. Baseline data for patients with CCTGA and controls are shown in Table 1. The mean age for subjects with CCTGA was $42.6 \pm$ 16 years compared with $39.7 \pm 14$ years for controls $(P=.5)$, with 11 of 25 men in both groups. There were
TABLE 2. Baseline characteristics of patients with congenitally corrected transposition of the great arteries

\begin{tabular}{lc}
\hline Underlying diagnosis & \\
Isolated CCTGA & $13(52 \%)$ \\
CCTGA, VSD, PS (repaired VSD) & $9(36 \%)$ \\
CCTGA, VSD, PS (open VSD) & $2(8 \%)$ \\
CCTGA, repaired VSD (no PS) & $1(4 \%)$ \\
NYHA class & \\
I & $11(44 \%)$ \\
II & $9(36 \%)$ \\
III & $3(12 \%)$ \\
IV & 0 \\
Unable to determine & $2(8 \%)$ \\
Right ventricular function & \\
Normal or mildly depressed & $15(60 \%)$ \\
Moderately depressed or greater & $10(40 \%)$ \\
Tricuspid insufficiency & \\
None or mild & $14(56 \%)$ \\
Moderate or greater & $7(28 \%)$ \\
Previous tricuspid valve replacement & $4(16 \%)$ \\
\hline
\end{tabular}

CCTGA, Congenitally corrected transposition of the great arteries; $N Y H A$, New York Heart Association; PS, pulmonary stenosis; VSD, ventricular septal defect.

no differences in marital status, employment status, and level of schooling between patients and controls. More patients with CCTGA than controls had undergone previous cardiac surgery $(14 / 25$ vs $8 / 25, P=.15)$ and pacemaker placement $(7 / 25$ vs $0 / 25, P=.01)$. Of the control patients, 14 of 25 had ventricular septal defects, and 11 of 25 had atrial septal defects. Of the 14 patients with ventricular septal defects, 4 had undergone surgical repair of significant defects, whereas 10 had small, hemodynamically insignificant defects. Of the 11 patients with atrial septal defects, 7 had undergone device closure, and 4 had undergone surgical closure. Cardiac status of patients with CCTGA is shown in Table 2. A variety of anatomic variants of CCTGA were present, including isolated CCTGA in 13 patients, CCTGA with repaired ventricular septal defect and pulmonary stenosis in 10 patients, CCTGA with pulmonary stenosis with open ventricular septal defect in 2 patients, and CCTGA with no pulmonary stenosis and repaired ventricular septal defect in 1 patient. The majority $(80 \%)$ of patients with CCTGA reported New York Heart Association class I or II symptoms. Right ventricular function was normal or mildly diminished in $60 \%$ of patients. In terms of tricuspid insufficiency, 4 patients $(16 \%)$ had undergone tricuspid valve replacement at the time of the survey, 14 patients $(56 \%)$ had no or mild tricuspid insufficiency, and 7 patients $(28 \%)$ had moderate or greater tricuspid insufficiency.

\section{Perceived Health Status}

Perceived health status and quality of life survey data are summarized in Table 3. No difference in perceived health status as measured by physical component and mental component summary scores of the SF-36 was seen between 
TABLE 3. Summary of results of measures for perceived health status and quality of life

\begin{tabular}{|c|c|c|c|}
\hline Instrument/demographic & $\begin{array}{l}\text { Controls } \\
(\mathbf{n}=\mathbf{2 5})\end{array}$ & $\begin{array}{l}\text { CCTGA patients } \\
(\mathbf{n}=\mathbf{2 5})\end{array}$ & $P$ value \\
\hline Age (mean, SD) & 39.7 & 42.6 & .5 \\
\hline $\operatorname{Sex}(\%$ male $)$ & $44 \%$ & $44 \%$ & 1.0 \\
\hline \multicolumn{4}{|l|}{ SF-36 } \\
\hline Physical functioning & $55(32-57)$ & $52.9(15-57)$ & .06 \\
\hline Role-physical & $56(35-56)$ & $56(28-56)$ & .19 \\
\hline Bodily pain & $56(29-63)$ & $56(42-63)$ & .69 \\
\hline General health & $53(28-64)$ & $49(44-60)$ & .08 \\
\hline Vitality & $56(44-63)$ & $51(23-61)$ & .22 \\
\hline Social function & $57(30-57)$ & $52(25-57)$ & .22 \\
\hline Role-emotional & $55(34-55)$ & $55(24-55)$ & .015 \\
\hline Mental health & $55(30-60)$ & $50(16-60)$ & .14 \\
\hline $\begin{array}{l}\text { Physical component } \\
\text { summary }\end{array}$ & $55(26-61)$ & $53(30-62)$ & .56 \\
\hline $\begin{array}{l}\text { Mental component } \\
\text { summary }\end{array}$ & $55(27-68)$ & $54(21-61)$ & .13 \\
\hline \multicolumn{4}{|l|}{ LAS* } \\
\hline QOL & $90(68-100)$ & $82(20-100)$ & .08 \\
\hline Health status & $85(65-100)$ & $80(15-100)$ & .03 \\
\hline SWLS & $29 \pm 4$ & $24 \pm 8$ & .009 \\
\hline
\end{tabular}

$P$ values of $<.05$ are shown in bold. Data are reported as median (range). $L A S$, Linear analog scale; $S D$, standard deviation; $S F-36$, Short Form 36 Health Survey; SWLS, satisfaction with life scale; $Q O L$, quality of life. $* \mathrm{~N}=24$ for LAS data.

patients with CCTGA and controls. Overall assessment of one's health status as measured by the general health subscale was higher in the control group (median score, 53; range, 28-64) compared with the CCTGA group (median score, 49; range, 44-60), although this difference did not achieve statistical significance $(P=.08)$. As measured by the LAS, perceived health status was higher in the control group (median score, 85; range, 65-100) compared with the CCTGA group (median score, 80; range, 15-100) $(P=.03)$.

\section{Quality of Life}

Patient-reported QOL as measured by the SWLS was higher in the control group (mean \pm standard deviation, $29 \pm 4)$ compared with patients with CCTGA $(24 \pm 8$, $P=.009)$. The median SWLS score of 29 in the control group is consistent with slightly above average QOL, whereas the median SWLS of 24 in the CCTGA is consistent with normal QOL. QOL as measured by the LAS was higher in controls (median, 90; range, 68100 ) than in individuals with CCTGA (median, 82; range, 20-100), although this difference did not reach statistical significance $(P=.08)$.

\section{Impact of Age on Health Status and Quality of Life}

In the control group, there was no correlation between age and measures of physical health status or QOL. There was a weak positive correlation between age and mental component summary score $(r=-0.4, P=.04)$. For patients with CCTGA, age was negatively correlated with the physical function subscale score $(r=-0.4, P=.04)$, bodily pain subscale score $(r=-0.5, P=.01)$, and physical component summary score of the SF-36 $(r=-0.6, P=.004)$. There was no correlation with age for patients with CCTGA or controls for the SWLS and LAS for health status and QOL.

\section{DISCUSSION}

This is the first study to specifically investigate patientreported health status and QOL in adults with CCTGA, demonstrating lower QOL and perceived health status by some measures in patients with CCTGA compared with a control group of patients with simple congenital heart disease. Although the majority of QOL studies report perceived health status or QOL for specific lesions compared with published normal values, this study involved the use of a control group with relatively simple repaired or hemodynamically insignificant congenital heart disease. Although some previous studies have shown lower perceived health status in patients with congenital heart disease, others have shown normal health status and QOL. ${ }^{11-15}$ There is some evidence that patients with congenital heart disease may have a higher than normal QOL and perceived health status. ${ }^{16}$ We sought to control for this issue by selecting a control group with relatively mild congenital heart disease, including patients with repaired atrial septal defect (both surgically and percutaneously), repaired ventricular septal defect, and small hemodynamically insignificant ventricular septal defects. The assumption was made that these lesions would not negatively affect measures of QOL and perceived health status. This did appear to be the case, because the SF-36 scores, LAS scores, and SWLS scores were consistently at or above reported values, the patient group values were consistently near or below reported normal values, and the control group values were consistently somewhat higher than normal values. This resulted in some measures of QOL and perceived health status being significantly lower in the CCTGA group than in the control group. The reason for the lower range of role emotional scores in the CCTGA group is unclear, because previous studies in adults with heart failure due to acquired heart disease have demonstrated that $81 \%$ of patients with heart failure have normal role emotional scores. ${ }^{17}$ Although the SF-36 can be faulted for being a generic instrument and not specific to congenital heart disease, an advantage is the ability to normalize the score and easily understand the relationship of scores for both the CCTGA and control group with normal values. There are limited data for congenital heart disease-specific instruments. ${ }^{18} \mathrm{Be}-$ cause congenital heart defects often involve long-term complications in addition to congestive heart failure, use of heart failure-specific instruments, such as the Minnesota 
Living with Heart Failure Questionnaire, does not seem appropriate. $^{19}$

The physiologic state of patients with CCTGA is comparable to that of patients with D-transposition of the great arteries after atrial switch procedures, in that both have a systemic right ventricle and a subpulmonary left ventricle. There are differences in the natural history, with atrial arrhythmias as a hallmark of the atrial switch, as well as other surgical issues, such as the potential for baffle leaks or stenosis. QOL and perceived health status measures for CCTGA as determined by the SWLS and LAS were comparable to values previously reported for patients with dextrotransposition of the great arteries after atrial switch repairs. ${ }^{2}$

\section{Impact of Advancing Age}

We demonstrated a modest negative correlation of some measures of QOL and health status with increasing age. This is not surprising because these patients have been known to do well the third or fourth decade of life when congestive heart failure develops in many. ${ }^{1}$ The potential for worsening QOL and health status with age is important in counseling patients as to the optimal treatment strategy for younger patients with congenitally corrected transposition.

\section{Implications}

The ultimate question is whether anatomic repairs convey long-term benefits in terms of survival, functional status, and QOL, which outweigh the early morbidity and mortality associated with these repairs. This study was not specifically designed to answer this question, but rather to determine the overall functional status and QOL of this patient population. In some ways, the study can be interpreted in a positive fashion, because perceived health status and QOL in patients with CCTGA were relatively good when compared with normal published values for the various measures. On the other hand, the decline in some measures of QOL and health status with advancing age is of concern, as is the fact that QOL measures are lower when controlling for a possible confounder of elevated perception of health status and QOL as a result of a congenital cardiac diagnosis. A study comparing QOL and school performance in children after the double-switch and Senning-Rastelli procedures demonstrated similar QOL parameters but lower school performance in children undergoing anatomic repairs for congenitally corrected transposition compared with those undergoing non-anatomic repairs. ${ }^{20}$ In addition, the need for follow-up surgical procedures, with their associated morbidity and mortality, is not uncommon after anatomic repairs. $^{21}$ Moving forward, a contemporary, prospective study of health status and QOL of patients undergoing anatomic repairs compared with traditional therapeutic strategies will be required as increasing numbers of patients who have undergone anatomic repairs reach adulthood.

\section{Limitations}

Several limitations of this study merit discussion. First, the relatively small sample size likely limited the ability of the study to demonstrate differences with the control group. The small sample size also makes it impossible to determine if specific subtypes of CCTGA could be associated differences in QOL or health status measures. Also, the cross-sectional study design raises the possibility of a survival bias. For example, one could argue that only patients with more favorable anatomic variants or right ventricular/atrioventricular valve status survived to be included in the analysis. This limits the applicability of the results to decision-making for a young patient who has not yet undergone any interventions. Finally, the study used relatively generic measures as opposed to diseasespecific QOL and health status instruments. Disease- and patient-specific QOL and health status measures are currently under development and should be considered in future studies.

\section{CONCLUSIONS}

Although perceived health status and patient-reported QOL are generally good and consistent with normal values, some measures of health status and QOL are lower in patients with CCTGA than in a control group of patients with hemodynamically insignificant disease.

\section{References}

1. Graham TP, Bernard YD, Mellen BG, Celermajer D, Baumgartner H, Fr Cetta, et al. Long-term outcome in congenitally corrected transposition of the great arteries. J Am Coll Cardiol. 2000;36:255-61

2. Moons P, De Bleser L, Budts W, Sluysmans T, De Wolf D, Massin M, et al. Health status, functional abilities, and quality of life after the Mustard or Senning operation. Ann Thorac Surg. 2004;77:1359-65.

3. Moons P, Van Deyk K, De Geest S, Gewillig M, Budts W. Is the severity of congenital heart disease associated with the quality of life and perceived health of adult patients? Heart. 2005;91:1193-8.

4. Ware JE, Sherbourne CD. The MOS 36 Item Short Form Health Survey (SF36).1. Conceptual framework and item selection. Med Care. 1992;30:473-83.

5. Ware JE, Kosinski M, Bayliss MS, McHorney CA, Rogers WH, Raczek A. Comparison of methods for the scoring and statistical analysis of SF 36 Health Profile and Summary Measures: Summary of results from the Medical Outcomes Study Med Care. 1995;33:AS264-79.

6. Ware JE, Kosinski M, Keller SK. SF- $36{ }^{\circledR}$ Physical and Mental Health Summary Scales: A User's Manual. Boston, MA: The Health Institute; 1994

7. Badia X, Monserrat S, Roset M, Herdman M. Feasibility, validity, and test-retest reliability of scaling methods for health states: the visual analog scale and the time trade-off. Qual Life Res. 1999;9:303-10.

8. Wewers ME, Lowe NK. A critical review of visual analogue scales in the measurement of clinical phenomena. Res Nurs Health. 1990;13:227-36.

9. Diener E, Emmons RA, Larsen RJ. Griffin. The satisfaction with life scale. J Pers Assess. 1985;49:71-5.

10. Pavot W, Diener E. Review of the satisfaction with life scale. Psychol Assessment. 1993;5:164-72.

11. Kamphuis M, Ottenkamp J, Vliegen HW, Vogels $\mathrm{T}$, Zwinderman $\mathrm{KH}$, Kamphuis RP, et al. Health related quality of life and health status in adult survivors with previously operated complex congenital heart disease. Heart 2002;87:356-62.

12. Ternestedt B, Wall K, Oddsson H, Riesenfeld T, Groth I, Schollin J. Quality of life 20 and 30 years after surgery in patients operated on for tetralogy of Fallo and for atrial septal defect. Pediatr Cardiol. 2001;22:128-32. 
13. Meijboom F, Szatmari A, Deckers JW, Utens EMWJ, Roelandt JRTC, Bos E, et al. Cardiac status and health-related quality of life in the long term after surgical repair of tetralogy of Fallot in infancy and childhood. J Thorac Cardiovasc Surg. 1995;110:883-91.

14. Lane DA, Lip GYH, Millane TA. Quality of life in adults with congenital heart disease. Heart. 2002;88:71-5.

15. Loup O, von Weissenfluh C, Gahl B, Schwerzmann M, Carrel T, Kadner A. Quality of life of grown-up congenital heart disease patients after congenital cardiac surgery. Eur J Cardiothorac Surg. 2009;36:105-11.

16. Moons P, Van Deyk K, De Bleser L, Marquet K, Raes E, De Geest S, et al. Quality of life and health status in adults with congenital heart disease: a direct comparison with healthy counterparts. Eur J Cardiovasc Prev Rehabil. 2006; 12:407-13.

17. Johansen JB, Pedersen SS, Spindler H, Andersen K, Nielsen JC, Mortensen PT. Symptomatic heart failure is the most important clinical correlate of impaired quality of life, anxiety, and depression in implantable cardioverter-defibrillator patients: a single-centre, cross-sectional study in 610 patients. Europace. 2008; 10:545-51.

18. Kamphuis M, Zwinderman KH, Vogels T, Vliegen HW, Kamphuis RP, Ottenkamp J, et al. A cardiac-specific health-related quality of life module for young adults with congenital heart disease: development and validation. Qual Life Res. 2004;13:735-45.

19. Rector TS, Kubo SH, Cohn JN. Patients' self assessment of their congestive heart failure. Part 2: content reliability and validity of a new measure, the Minnesota Living with Heart Failure Questionnaire. Heart Failure. 1987;3: 198-209.

20. Gaies MG, Watnik CS, Gurney JG, Bove EL, Goldberg CS. Health-related quality of life in patients with congenitally corrected transposition of the great arteries. J Thorac Cardiovasc Surg. 2011 Jan 28 [Epub ahead of print].

21. Gaies MG, Goldberg CS, Ohye RG, Devaney EJ, Hirsch JC, Bove EL. Early and intermediate outcome after anatomic repair of congenitally corrected transposition of the great arteries. Ann Thorac Surg. 2009;88:1952-60. 